\title{
An unusual case of ectopic corticotrophin- releasing hormone syndrome caused by an adrenal noncatecholamine-secreting pheochromocytoma: a case report
}

\author{
Bao-Ping Wang ${ }^{1}$, Lei-Lei Yang ${ }^{2}$, Hao Wang ${ }^{1}$, Qing He ${ }^{1}$, Zhong-Shu Ma ${ }^{1}$, Yi Lin ${ }^{3}$, Chang-Xin Jiang ${ }^{4}$,
} Hao-Ran Sun ${ }^{5}$ and Ming Liu ${ }^{1 *}$

\begin{abstract}
Background: Pheochromocytoma, especially for noncatecholamine-secreting pheochromocytoma, is an extremely rare cause of ectopic corticotrophin-releasing hormone $(\mathrm{CRH})$ syndrome.

Case presentation: A 27-year-old Chinese woman was administered dexamethasone for a skin allergy, but her general condition rapidly deteriorated over a month. She was subsequently hospitalized for typical clinical features of Cushing's syndrome. Endocrinological investigation confirmed severe hypercortisolism along with elevated plasma adrenocorticotropin hormone (ACTH). However, magnetic resonance imaging (MRI) revealed no pituitary adenoma. Abdominal contrast-enhanced computed tomography (CT) revealed a $6.5 \mathrm{~cm}$ heterogeneous right adrenal mass with mildly contrast enhancement. The tumor was found during a routine physical check-up at a local hospital 16 months ago; however, the patient did not have any symptoms and did not seek further medical attention at that time. Laparoscopic resection of the right adrenal tumor led to a rapid remission of Cushing's syndrome. Based on pathological findings and the presence of normal catecholamine metabolites in her serum and urine, the patient was diagnosed with noncatecholamine-secreting pheochromocytoma. Immunohistochemical staining of the adrenal tumor revealed positive staining for $\mathrm{CRH}$ and negative staining for $\mathrm{ACTH}$.
\end{abstract}

Conclusions: This is an extremely rare case of ectopic CRH syndrome caused by an adrenal noncatecholamine-secreting pheochromocytoma. Both ectopic ACTH syndrome and ectopic CRH syndrome should be considered in patients presenting with ACTH-dependent Cushing's syndrome caused by extrapituitary diseases.

Keywords: Adrenocorticotropin, Dexamethasone, Ectopic CRH syndrome, Pheochromocytoma, Noncatecholamine secreting

\section{Background}

Cushing's syndrome is classified as either ACTH-independent or ACTH-dependent, which can be further classified as either Cushing's disease or ectopic ACTH syndrome (EAS). EAS accounts for $10-20 \%$ of all cases of Cushing's syndrome [1]. The most common origins of the tumors responsible for EAS are the lungs (45\%), thymus (11\%), pancreas (8\%), and thyroid (6\%) [2]. Pheochromocytoma accounts for approximately $5 \%$ of

\footnotetext{
* Correspondence: mingliu@tmu.edu.cn

${ }^{1}$ Department of Endocrinology and Metabolism, Tianjin Medical University General Hospital, No 154 Anshan Road, Heping District, Tianjin 300052, China Full list of author information is available at the end of the article
}

EAS cases [2]. Approximately $1.3 \%$ of all identified pheochromocytomas have ectopic ACTH secretion [3]; in rare cases, the ectopically secreted hormone is $\mathrm{CRH}$, with ACTH being secreted by the pituitary gland [4]. To date, only one case has been reported where a patient with an ectopic $\mathrm{CRH}$-secreting pheochromocytoma had normal catecholamine metabolites [5]. Dexamethasone has negative feedback on CRH gene expression and secretion in the hypothalamus. However, dexamethasone could stimulate CRH expression in the placenta and the bed nucleus of the stria terminalis, suggesting that dexamethasone regulation might be tissue-specific [6]. Here, we reported a patient with ectopic $\mathrm{CRH}$ syndrome

(c) The Author(s). 2018 Open Access This article is distributed under the terms of the Creative Commons Attribution 4.0 International License (http://creativecommons.org/licenses/by/4.0/), which permits unrestricted use, distribution, and reproduction in any medium, provided you give appropriate credit to the original author(s) and the source, provide a link to the Creative Commons license, and indicate if changes were made. The Creative Commons Public Domain Dedication waiver (http://creativecommons.org/publicdomain/zero/1.0/) applies to the data made available in this article, unless otherwise stated. 
caused by an adrenal noncatecholamine-secreting pheochromocytoma that was associated with a use of dexamethasone.

\section{Case presentation}

Prior to this admission, a 27-year-old woman sought medical attention at a local hospital because of facial redness and edema caused by eating a mango. She was treated with dexamethasone ( $5 \mathrm{mg}$ intravenously daily) for five days. The patient gradually developed a round face, acne, hirsutism, hypokalemia, and $5 \mathrm{~kg}$ of weight loss over the course of one month since receiving dexamethasone. Upon hospitalization, the patient presented with a one-month history of facial edema, weight loss, and acne. She had no family history of Cushing's syndrome, pheochromocytoma, or multiple endocrine neoplasia type 2 . A $5.5-\mathrm{cm}$ mass located in the right posterior lobe of the liver was detected by ultrasound in a routine physical examination 16 months ago at a local hospital; however, the patient had no symptom and did not seek further medical attention at that time.

The patient's blood pressure was $120 / 75 \mathrm{mmHg}$ in both arms in the supine position, with a regular pulse of $76 \mathrm{bpm}$. Her height was $164 \mathrm{~cm}$ and her weight was $48 \mathrm{~kg}$ (body mass index: $17.8 \mathrm{~kg} / \mathrm{m}^{2}$ ). The patient had "moon face" and severe facial edema, beard, central deposition of fat with slim extremities and atrophic muscles, and no pretibial edema. The skin was diffused with acne and both armpits had hyperpigmentaion.

Laboratory tests revealed marked hypokalemia $(2.1 \mathrm{mmol} /$ $\mathrm{L}$; normal range, $3.5-5.5 \mathrm{mmol} / \mathrm{L}$ ), which could not be normalized with oral and intravenous potassium supplementation until spironolactone was added. A 75-g oral glucose tolerance test confirmed diabetes mellitus with a fasting blood glucose level of $9.19 \mathrm{mmol} / \mathrm{l}$ and a 2-h glucose level of $21.66 \mathrm{mmol} / \mathrm{L}$, with a HbA1c level of $6.3 \%$. She was started on insulin aspart30 (48 U daily).

Endocrinological investigation identified severe hypercortisolism with loss of circadian rhythm. Plasma ACTH level was elevated to $1157 \mathrm{pg} / \mathrm{mL}$, confirming ACTHdependent Cushing's syndrome. Except for testosterone, the catecholamine metabolites, growth hormone, calcitonin, and prolactin levels were all within the normal range (Table 1).

MRI and contrasted MRI revealed no pituitary adenoma and EAS was considered. Abdominal contrast-enhanced CT scanning revealed that the mass lesion was located in the right adrenal gland and not in the right hepatic posterior lobe. The mass was a heterogeneous solid tumor which was mildly enhanced with some patchy nonenhancing areas (Fig. 1a). PET/CT showed moderate fluorodeoxyglucose (FDG) uptake in the mass (Fig. 1b). Both contrasted CT and PET-CT revealed bilateral adrenal hyperplasia, but the neck, thorax, and pelvis were normal.
Table 1 Laboratory findings of pertinent hormones

\begin{tabular}{|c|c|c|c|}
\hline & $\begin{array}{l}\text { Baseline } \\
\text { value }\end{array}$ & $\begin{array}{l}\text { Overnight dexamethasone } \\
\text { suppression test }\end{array}$ & Normal range \\
\hline Serum cortisol & & & $5-25 \mu \mathrm{g} / \mathrm{dL}$ \\
\hline $08: 00 \mathrm{~h}$ & $>50$ & $>50$ & \\
\hline $16: 00 \mathrm{~h}$ & $>50$ & & \\
\hline $00: 00 \mathrm{~h}$ & $>50$ & & \\
\hline Urine free cortisol & $>2000$ & & $30-110 \mu g / 24 h$ \\
\hline ACTH & & & $0-46 \mathrm{pg} / \mathrm{mL}$ \\
\hline $08: 00 \mathrm{~h}$ & 1157 & 625 & \\
\hline $16: 00 \mathrm{~h}$ & 459 & & \\
\hline $00: 00 \mathrm{~h}$ & 350 & & \\
\hline VMA & 20.5 & & $<72 \mu \mathrm{mol} / 24 \mathrm{~h}$ \\
\hline Metanephrine & 0.15 & & $\leq 0.5 \mathrm{nmol} / \mathrm{L}$ \\
\hline Normetanephrine & 0.13 & & $\leq 0.9 \mathrm{nmol} / \mathrm{L}$ \\
\hline FSH & 5.36 & & $2.5-10.2 \mathrm{IU} / \mathrm{L}$ \\
\hline LH & 0.4 & & $1.9-12.5$ IU/L \\
\hline $\mathrm{GH}$ & 0.12 & & $0.06-5 \mathrm{ng} / \mathrm{mL}$ \\
\hline PRL & 0.3 & & $2.8-29.2 \mathrm{ng} / \mathrm{mL}$ \\
\hline T & 154.9 & & $14-76$ ng/dL \\
\hline E2 & 26.18 & & $19-144 \mathrm{pg} / \mathrm{mL}$ \\
\hline$C T$ & $<2$ & & $0-5 \mathrm{pg} / \mathrm{mL}$ \\
\hline TSH & 0.014 & & $0.3-5.0 \mathrm{IU} / \mathrm{mL}$ \\
\hline FT4 & 11.94 & & $11.5-23.5 \mathrm{ng} / \mathrm{dL}$ \\
\hline FT3 & 2.21 & & $3.5-5.5 \mathrm{ng} / \mathrm{dL}$ \\
\hline rT3 & 0.34 & & $0.2-0.4 \mathrm{ng} / \mathrm{mL}$ \\
\hline
\end{tabular}

VMA: 24-hurinary vanillylmandelicacid; FSH: follicle-stimulating hormone; $\mathrm{LH}$ : luteinizing hormone; E2: estradiol; CT: calcitonin; PRL: prolactin; T: testosterone; FT3: free thyroxin; FT4: free triiodothyronine; TSH: thyroid stimulating hormone; rT3: reverse thyroxin

We prepared to do inferior petrosal sinus sampling (IPSS) for ACTH assays, adrenal vein sampling for $\mathrm{ACTH}$ assays to make out the origin of ACTH. But the patient's general condition rapidly deteriorated after admission, Adrenal tumorectomy was performed. During surgery, when the right adrenal mass was mobilized, no hypertensive crisis occurred. A 6.5 -cm black mass was found arising from the medial branch of the right adrenal gland (Fig. 2a). Hematoxylin-eosin staining of the tumor revealed that most of the cells were chromaffin-like cells. In addition, there were multifocal oval eosinophilic cells under the tumor capsule (Fig. 2b). Immunohistochemical staining showed positive staining for chromogranin A (CgA) (Fig. 2c) and CD56 (Fig. 2d), with a Ki67 labeling index of approximately $16 \%$ (Fig. 2e) for chromaffin-like cells. No positive ACTH immunostaining was noticed (Fig. 2f). Positive immunostaining for $\mathrm{CRH}$ and Melan-A (Fig. 2g and $\mathrm{h}$ ) and negative immunostaining for $\mathrm{CgA}$ and CD56 were found in the eosinophilic cells, indicating that 


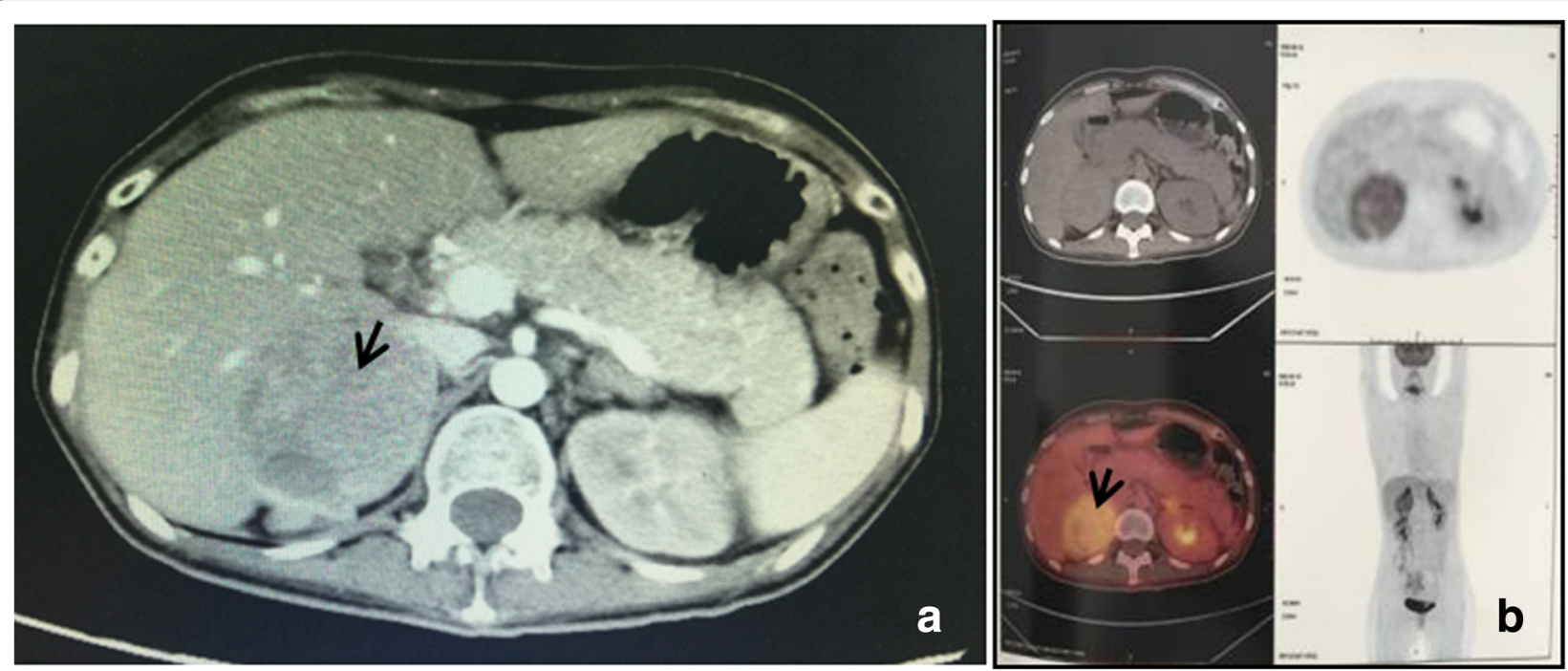

Fig. 1 The CT and PET/CT image of the adrenal pheochromocytoma. a Abdominal contrast-enhanced CT revealing a mass with a diameter $6.5 \mathrm{~cm}$ in the right adrenal gland. The mass was a heterogeneous solid tumor which was mildly enhanced with some patchy nonenhancing areas (arrow). b PET/CT showed moderate FDG uptake in the right adrenal mass(arrow)

$\mathrm{CRH}$ production is indeed derived from the tumor's peripheral cells.

One day after surgery, ACTH levels had decreased from 715 to $14.3 \mathrm{pg} / \mathrm{ml}$ and serum cortisol level had decreased from more than 50 to $10.4 \mu \mathrm{g} / \mathrm{dl}$. One week postoperatively, blood potassium and glucose levels normalized without the need for medication. The signs and symptoms of Cushing's syndrome gradually disappeared within two months, and the hydrocortisone supplementation (initial dosage was $60 \mathrm{mg}$ daily and tapered gradually) was discontinued seven weeks postoperatively. CT revealed that the left adrenal gland was almost reduced to the normal size three months later. The patient is currently under regular follow-up and remains well nine months after surgery.

\section{Discussion}

EAS is rare, with approximately $5 \%$ of all cases caused by pheochromocytoma [2]. In our patient, a diagnosis of EAS was suggested by the relatively short history, severe Cushing's syndrome associated with refractory hypokalemia, the absence of a definitive lesion on the pituitary MRI scan, and the extremely elevated plasma ACTH levels. Histology confirmed that the right adrenal mass was a pheochromocytoma. The clinical features and the presence of normal catecholamine metabolites in the patient's serum and urine confirmed the presence of a noncatecholamine-secreting pheochromocytoma. Chen et al. proposed criteria for the diagnosis of ACTH-secreting pheochromocytomas [7]. Except for the biochemical evidence of pheochromocytoma, this case satisfied all criteria for ACTH-secreting pheochromocytoma.
Some CRH-secreting tumors (pheochromocytoma in this case) could be misdiagnosed as ACTH-secreting tumors because preoperative inferior petrosal sinus sampling (IPSS) for ACTH assays, adrenal vein sampling for $\mathrm{ACTH}$ and $\mathrm{CRH}$ assays, and postoperative immunostaining for $\mathrm{ACTH}$ and $\mathrm{CRH}$ are not routinely performed. Quinton et al. reported three patients with ACTH-dependent Cushing's syndrome; in two cases, immunostaining showed reactivity for $\mathrm{CRH}$ instead of $\mathrm{ACTH}$, supporting $\mathrm{CRH}$ (or related peptide) -secreting pheochromocytoma [8]. In the current case, the patient's rapidly deteriorating condition did not allow us to perform IPSS and adrenal vein sampling. Yet, negative immunostaining for ACTH and positive immunostaining for $\mathrm{CRH}$ strongly suggested that the elevated ACTH resulted from an adrenal $\mathrm{CRH}$-secreting pheochromocytoma.

Studies have reported that EAS and ectopic CRH syndrome have different effects on the hypothalamic-pituitary-adrenal axis [8]. Post-operative recovery from the clinical symptoms and elevated cortisol levels is much faster in patients with ectopic $\mathrm{CRH}$ syndrome than in those with ectopic ACTH syndrome $[5,8]$. In the present case, the rapid postoperative recovery of clinical features, elevated serum ACTH, potassium and glucose levels, and short-term application of prednisone supported the classification of the pheochromocytoma as a CRH-secreting tumor, with ACTH secreted from the pituitary gland. Pathological evidence, clinical presentations, and outcomes supported the ectopic CRH syndrome diagnosis.

An ectopic CRH-secreting pheochromocytoma is an extremely rare cause of ACTH-dependent Cushing's syndrome. The first case of isolated ectopic CRH-secreting 


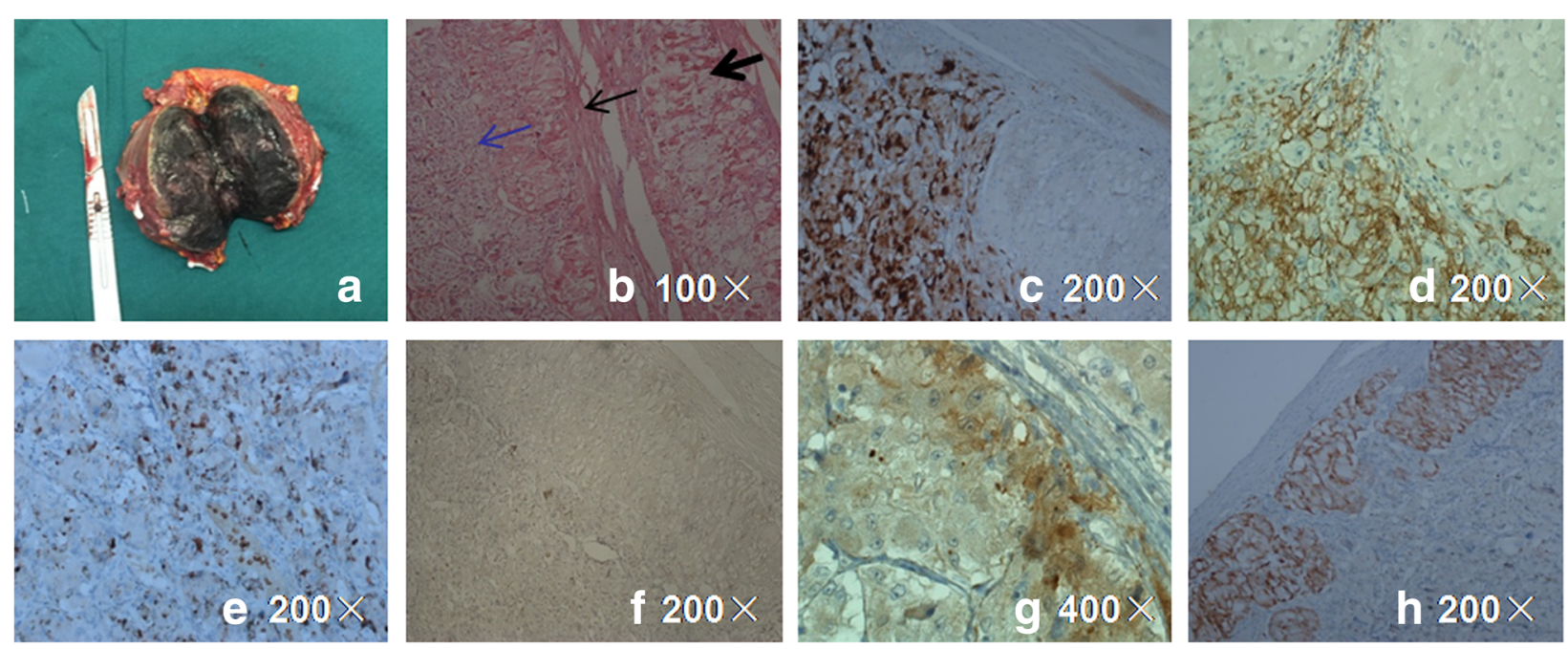

Fig. 2 External appearance and histopathology of the pheochromocytoma. a External appearance of the resected tumor, $6.5 \mathrm{~cm}$ in diameter and black in color, from the medial branch of right adrenal gland with enlargement of the lateral branch. $\mathbf{b}$ Histopathology revealed that the majority of cells were chromaffin-like cells with a very rich vascular sinus (thin blue arrow). Beneath the tumor capsule, there were multifocal oval eosinophilic cells with oval nucleus (thin black arrow). Adrenocortical hyperplasia was also revealed (bold black arrow; HE staining, 100x). Positive immunohistostaining is shown for CgA (c 200x), CD56 (d 200x), and Ki67 (e 100x) for chromaffin-like cells. No positive ACTH immunostaining was noticed (f 200x). Positive immunohistostaining is shown for CRH (g 400x) and Melan-A (h 200x) in the eosinophilic cells

pheochromocytoma was reported in 1999 [4]. To date, six cases of isolated ectopic $\mathrm{CRH}$-secreting pheochromocytoma and three cases of ectopic ACTH/CRH co-secreting pheochromocytoma have been reported [4, 5, 8-13]. Usually, a pheochromocytoma produces catecholamines and causes symptoms such as hypertension [14]. Among these six cases of isolated $\mathrm{CRH}$-secreting pheochromocytoma, only one case had normal plasma and urinary epinephrine, normetanephrine, and metanephrine concentrations [5]. Although there is no record of hypertensive crisis during surgery, the event cannot be completely ruled out for functional pheochromocytoma because the patient was treated preoperatively with the somatostatin analog octreotide [5]. In the current case, the lack of catecholamine hypersecretion, the clinical manifestations, and the consistently normal blood and urinary levels of catecholamines and their metabolites provided no indication of a pheochromocytoma. To our knowledge, this is the second reported case of Cushing's syndrome caused by ectopic CRH secreted from an adrenal noncatecholaminesecreting pheochromocytoma.

In this case, the patient had an adrenal tumor without any symptoms for 16 months before this hospitalization. The typical clinical features of Cushing's syndrome appeared to be associated with administration of dexamethasone that was used to treat a skin allergy caused by eating mango. To our knowledge, mangoes or allergies have no effect on CRH synthesis and secretion, but this is not true for dexamethasone. Dexamethasone has negative feedback on hypothalamus CRH gene expression and secretion, but tissue-specific regulation of dexamethasone on CRH gene expression and secretion may exist. Indeed, glucocorticoids could stimulate $\mathrm{CRH}$ synthesis and secretion in the human placenta [6], and dexamethasone could up-regulate $\mathrm{CRH}$ gene expression in the pheochromocytoma [13]. In this case, a pre-existing tumor, chronological dexamethasone administration, and clinical symptoms and signs suggested that dexamethasone might induce $\mathrm{CRH}$ gene expression and/or secretion in the adrenal pheochromocytoma, thereby may provoke ectopic CRH syndrome. However, due to lack of blood tests before onset of symptom, we cannot rule out the possibility that the patient might have mild hypercortisolism before dexamethasone administration. Nevertheless, the current case suggests that performing dexamethasone suppression test may need to be evaluated if ectopic CRH syndrome is considered.

This study has several limitations. First, owing to the lack of a CRH assay, plasma CRH levels were not measured. Therefore, there was no direct evidence of elevated plasma CRH levels in this patient. Second, because the patient's condition rapidly deteriorated, pre-surgery IPSS and adrenal vein sampling for measuring ACTH were not performed, which could have provided direct evidence of the source of elevated ACTH. Finally, dexamethasone's effect on the onset and development of ectopic CRH syndromes was postulated based on the chronology of dexamethasone administration and presentation of clinical features and syndromes. Further experimental studies are warranted to confirm the tissue-specific regulation of dexamethasone on $\mathrm{CRH}$ expression and secretion. 


\section{Conclusions}

In conclusion, we report an extremely rare case of ectopic $\mathrm{CRH}$ syndrome caused by an adrenal noncatecholaminesecreting pheochromocytoma. Both ectopic ACTH syndrome and ectopic CRH syndrome should be considered in patients presenting with ACTH-dependent Cushing's syndrome caused by extrapituitary diseases.

\section{Abbreviations}

ACTH: Adrenocorticotropin hormone; $\mathrm{CRH}$ : Corticotrophin-releasing hormone; CT: Computed tomography; EAS: Ectopic ACTH syndrome; FDG: Fluorodeoxyglucose; IPSS: Inferior petrosal sinus sampling; MRI: Magnetic resonance imaging; PET: Positron emission tomography

\section{Acknowledgements}

We are very thankful to Qian Wang for immunohistochemical staining of $\mathrm{ACTH}$ and CD56, Xin Zhang for immunohistochemical staining of $\mathrm{CRH}$.

\section{Funding}

This research did not receive any specific grant from any funding agency in the public, commercial, or not-for-profit sector.

\section{Availability of data and materials}

The datasets analyzed during the current study are available from the corresponding author on reasonable request.

\section{Authors' contributions}

B-PW, L-LY, HW and YL made the diagnosis, treatment, follow-up and wrote the manuscript. QH, Z-SM and ML reviewed literature, drafted the manuscript, and reviewed the manuscript for final publication. $\mathrm{H}-\mathrm{RS}$ and $\mathrm{C}-\mathrm{XJ}$ performed the histological examination of the tumor and reviewed the manuscript for final publication. All authors read and approved the final manuscript.

\section{Ethics approval and consent to participate}

Ethical approval for this study was obtained from the Ethics Committee of Tianjin Medical University General Hospital, Tianjin China (No. IRB2016-YX-050) Informed consent was obtained from the patient.

\section{Consent for publication}

Written informed consent was obtained from the patient for publication of this case report and any accompanying images.

\section{Competing interests}

The authors declare that they have no competing interests.

\section{Publisher's Note}

Springer Nature remains neutral with regard to jurisdictional claims in published maps and institutional affiliations.

\section{Author details \\ ${ }^{1}$ Department of Endocrinology and Metabolism, Tianjin Medical University General Hospital, No 154 Anshan Road, Heping District, Tianjin 300052, China. ${ }^{2}$ Department of Gerontology, Beijing ChuiYangLiu Hospital (Chui Yang Liu Hospital affiliated to TsingHua University), Beijing 100022, China. ${ }^{3}$ Department of Urology, Tianjin Medical University General Hospital, No 154 Anshan Road, Heping District, Tianjin 300052, China. ${ }^{4}$ Department of Pathology, Tianjin Medical University General Hospital, No 154 Anshan Road, Heping District, Tianjin 300052, China. ${ }^{5}$ Department of Medical Imaging, Tianjin Medical University General Hospital, No 154 Anshan Road, Heping District, Tianjin 300052, China.}

Received: 21 July 2017 Accepted: 8 June 2018

Published online: 19 June 2018

\section{References}

1. Isidori AM, Kaltsas GA, Pozza C, Frajese V, Newell-Price J, Reznek RH, et al. The ectopic Adrenocorticotropin syndrome: clinical features, diagnosis, management, and long-term follow-up. The Journal of Clinical Endocrinology \& Metabolism. 2006;91:371-7.
2. Isidori AM, Lenzi A. Ectopic ACTH syndrome. Arq Bras Endocrinol Metab. 2007:51:1217-25.

3. Alhammar H, Calissendorff J, Höybye C. Frequency of Cushing's syndrome due to $\mathrm{ACTH}$-secreting adrenal medullary lesions: a retrospective study over 10 years from a single center. Endocrine. 2017;55:296-302.

4. Eng PHK, Tan LHC, Wong KS, Cheng CWS, Fok ACK, Khoo DHC. Cushing's syndrome in a patient with a corticotropin-releasing hormone-producing pheochromocytoma. Endocr Pr. 1999;5:84-7.

5. Ruggeri RM, Ferraù F, Campennì A, Simone A, Barresi V, Giuffrè G, Tuccari G, Baldari STF. Immunohistochemical localization and functional characterization of somatostatin receptor subtypes in a corticotropin releasing hormonesecreting adrenal phaeochromocytoma: review of the literature and report of a case. Eur J Histochem. 2009:53:1-6.

6. Kageyama K, Hanada K, Takayasu S, Iwasaki Y, Sakihara S, Nigawara TST. Involvement of regulatory elements on corticotropin-releasing factor gene promoter inhypothalamic 4B cells. J Endocrinol Investig. 2008;31:1078-85.

7. Chen H, Doppman JL, Chrousos GP, Norton JA, Nieman LKUR. Adrenocorticotropic hormone-secreting pheochromocytomas: the exception to the rule. Surgery. 1995;118:994-5

8. Lois KB, Santhakumar A, Vaikkakara S, Mathew S, Long A, Johnson SJ, et al. Phaeochromocytoma and ACTH-dependent cushing's syndrome: tumour crf secretion can mimic pituitary cushing's disease. Clin Endocrinol. 2016;84:177-84.

9. Bayraktar F, Kebapcilar L, Kocdor MA, Asa SL, Yesil S, Canda S, Demir T, Saklamaz A, Seçil M, Akinci B, Yener SCA. Cushing's syndrome due to ectopic $\mathrm{CRH}$ secretion by adrenal pheochromocytoma accompanied by renal infarction. Exp Clin Endocrinol Diabetes. 2006;114:444-7.

10. Mondello S, Fodale V, Cannavo S, Aloisi C, Almoto B, Buemi M, et al. Hypophosphatemia as unusual cause of ARDS in Cushing's syndrome secondary to ectopic CRH production. A case report. Sci World J. 2008;8:138-44.

11. Jessop DS, Cunnah D, Millar JG, Neville E, Coates P, Doniach I, Besser GMRL. A phaeochromocytoma presenting with Cushing's syndrome associated with increased concentrations of circulating corticotrophin-releasing factor. J Endocrinol. 1987:113:133-8.

12. O'Brien T, Young WF Jr, Davila DG, Scheithauer BW, Kovacs K, Horvath E, et al. Cushing's syndrome associated with ectopic production of corticotrophin-releasing hormone, corticotrophin and vasopressin by a phaeochromocytoma. Clin Endocrinol. 1992;37:460-7.

13. Liu J, Päivi H, Voutilainen R, Karonen S-L, Kahri Al. Pheochromocytoma expressing adrenocorticotropin and corticotropin-releasing hormone; regulation by glucocorticoids and nerve growth. Eur J Endocrinol. 1994;131:221-8.

14. Pacak K, Linehan WM, Eisenhofer G, Walther MM, Goldstein DS. Recent advances in genetics, diagnosis, localization, and treatment of Pheochromocytoma. Ann Intern Med. 2001;134:315-29.
Ready to submit your research? Choose BMC and benefit from:

- fast, convenient online submission

- thorough peer review by experienced researchers in your field

- rapid publication on acceptance

- support for research data, including large and complex data types

- gold Open Access which fosters wider collaboration and increased citations

- maximum visibility for your research: over $100 \mathrm{M}$ website views per year

At BMC, research is always in progress.

Learn more biomedcentral.com/submissions 